Collection: NFZ Summer School 2009 - Birmensdorf (Switzerland)

Long-term ecosystem research: understanding the present to shape the future Guest Editor: Marcus Schaub (WSL, Switzerland)

\section{Remote sensing-supported vegetation parameters for regional climate models: a brief review}

\begin{abstract}
Latifi $\mathrm{H}^{(1)}$, Galos B ${ }^{(2)}$
Land surface plays a key role in a climate system. Thus, the land surface description will become increasingly important for climate modelling by its feedbacks on the climate. Various forms of active/passive remotely sensed data are nowadays being used to provide continuous and up-to-date information on the earth's surface on both global and regional scales. This information is useful to be included in climate models. This review summarizes how LAl and albedo, two of the most important land surface parameters, could be derived from remote sensing. Whereas the high acquisition frequency, accessibility, and spatial continuality are referred to potential advantages, the scaling is still a drawback which may cause further problems such as incompatibility of different remote sensing data sources for a specific climate model. Moreover, issues like shadow and atmospheric effects are often problematic, especially when optical remote sensing is applied. Here, suggestions for improvement are made and open questions are pointed out.
\end{abstract}

Keywords: Regional climate models, Forest and vegetation parameters, Active and passive remote sensing

\section{Introduction}

Climate projections for the $21^{\text {st }}$ century show an increase in near surface temperatures across Europe (Giorgi \& Bi 2005, Déqué et al. 2005). The probability of extreme events, i.e., floods, heat waves, and droughts, are also predicted to increase near in the future (e.g., Christensen \& Christensen 2003, Schär et al. 2004, Seneviratne et al. 2006). Modelling studies have shown the influence of land surface characteristics on climate simulations (Pitman 2003, Brovkin et al. 2006) that can alter the climate change

(1) Dept. of Remote Sensing and Landscape Information Systems, University of Freiburg, Tennenbacher straße 4, D-79106 Freiburg (Germany); (2) Institute of Environment and Earth Sciences, Faculty of Forestry, University of West Hungary, 9400 Sopron (Hungary)

@ Hooman Latifi (hooman.latifi@felis.unifreiburg.de)

Received: May 25, 2010 - Accepted: May 31, 2010

Citation: Latifi H, Galos B, 2010. Remote sensing-supported vegetation parameters for regional climate models: a brief review. iForest 3: 98-101 [online: 2010-07-15] URL: http://www.sisef.it/iforest/show.php? id $=543$ signal. On a finer scale, the land surface description will become increasingly important due to feedback effects on the local climate. Information about land cover can be gathered from either terrestrial measurements or remote sensing.

Following the launch of the first earth observation satellite in 1972, information extracted from remote sensing has been applied by environmental scientists as a continuous and up-to-date source of spectral/spatial data to represent different attributes of the earth surface in general, as well as vegetation cover in particular. The present review focuses on integrating monitoring and remote sensing methods for improved representation of forest cover in climate models. Two important vegetation-related land-cover attributes including Leaf Area Index (LAI) and background albedo (i.e., the albedo of a snow-free surface) have been selected to illustrate how they could be derived using methods based on airborne/space borne remote sensing data. In addition, an example is given of their practical application in a regional climate model.

\section{The role of LAI and Albedo in the} land surface processes

Climate determines the spatial distribution of forests, which is affected by climate change (e.g., Mátyás 2008). In turn, forests modify water and energy exchanges between land and atmosphere due to their Leaf Area Index (LAI), lower albedo and higher roughness length. Here, LAI and albedo have been selected as two key parameters in climate models which can be routinely derived from remote sensing data products. According to NASA definition, LAI is the one-sided green leaf area per unit ground area in broadleaf vegetation canopies, which is approximated by half the total needle surface area in coniferous canopies (see NASA-LAI http://modis-land.gsfc.nasa.gov/lai.htm). In climate models, LAI influences evapotranspiration and the precipitation interception capacity, which are the major components of the surface thermal and moisture balance of the hydrological cycle. It is a driver for many other vegetation exchange processes such as photosynthesis (Wilfong et al. 1967) and carbon flux (Inoue \& Olioso 2004). LAI is also a major indicator of stress in forests.

Solar radiation is the main source of energy for the global climate system. After interacting with the atmosphere, where the radiation is partly absorbed and partly scattered, a fraction of the incoming solar radiation is absorbed at the earth's surface. The remainder is reflected back to the atmosphere. The ratio of this reflected energy to the incoming radiation is called the surface albedo (Post et al. 2000). Albedo describes radiation processes at the atmosphere-land surface boundary and determines the energy budget of the earth's surface in the models.

\section{Deriving LAI from remote sensing}

Remote sensing data and techniques can complement existing ground-based measurement of LAI. In other words, measurements extracted from remotely sensed data are generally referred to as "indispensable components", which are necessary for modelling and simulating ecological variables and processes (Zheng \& Moskal 2009). The consistency of LAI over different spatial resolutions makes it an ecologically-relevant parameter for multi-scale research that ranges from leaf to landscape, and to regional scales (Wulder \& Franklin 2003).

Both active (detection of the reflected or emitted electromagnetic radiation from natural energy sources) and passive (detection of reflected responses from objects that are irradiated from artificially-generated energy sources) remote sensing forms have been used to retrieve LAI on various spatial scales. Despite the possible biases in estimating LAI as a result of shadow effects in forest canopies, airborne optical sensors have been widely used for LAI extraction from fine-scale airborne imagery, either for modelling the time-course of LAI (e.g., Kotz 
et al. 2004, Gonzalez-Sanpedro et al. 2008) or to correlate the remotely sensed spectral features and LAI measured on the ground (e.g., Wardley \& Curran 1984, McAllister \& Valeo 2007, Lee et al. 2004).

To relate LAI and different pixel-based vegetation indices (e.g., Normalized Difference Vegetation Index), various regression techniques have been applied. These techniques estimate LAI from the spectral indices like NDVI on a regional and landscape scale, mainly using visible/infrared Landsat data (Cohen et al. 2003, Soudani et al. 2006). Though the use of satellite data in LAI retrieval may be affected by problems such as the nonlinearity of the LAI/vegetation index relationship (which forces the use of nonlinear models) or background reflections in pixel values (which might cause biased LAI estimation), medium resolution satellite data are extensively used as a valuable LAI source for regional climate models.

Active remote sensing forms, i.e., Radio Detection and Ranging (RADAR) and more recently Light Detection and Ranging (LiD$A R$ ), have also been used to obtain useful information about the structural and physical dimensions of forests and other types of land cover. To ensure the independence of active remote sensing systems from cloud cover and the saturation of vegetation index, they are generally used instead of (or together with) optical remote sensing forms. Only occasionally, RADAR data (Brakke et al 1981) as well as LiDAR (Kwak et al. 2007, Pang et al. 2009) have been used in LAI retrieval on regional scales. Pang et al. (2009) found that different forest types (needle leaf and broadleaf) show different relationships between LiDAR return ratio and LAI. Yet, they evaluated the data as a suitable source for large scale mapping of LAI in forests, as it was strongly correlated to field-measured LAI.

\section{Background albedo from remote sensing}

Although point measurements can be made with field observations, remote sensing offers a reliable and accurate way to estimate albedo on a regional scale. Given appropriate atmospheric modelling tools, optical remote sensing instruments can measure the surface reflectance in particular directions and illumination angles dictated by the scanning mechanism and the trajectory characteristics of the platform. Lewis et al. (1999) used the data from an Airborne Solid-state Imaging Spectrometer (ASAS) to estimate integrated reflectance properties related to albedo. The results were compared with the results of a linear model of surface bi-directional reflectance and validated using the field-recorded albedo measurements. The ASAS-derived albedo agreed well with those collected in the field.
Surface albedo has also been derived from medium-resolution remote sensing features (mainly in the visible/near infrared domain). This has been tested, optimized and calibrated by other studies to be used in regional climate models (e.g., Liu et al. 1994, Kawata \& Ueno 1995, Lucht et al. 2000, Richter et al. 2008).

Albedo has already been estimated on micro scale. However, its values tend to vary as the scale becomes coarser. This makes it difficult to model it on macro scales, particularly when terrestrial ecosystems are monitored. For example, Liu et al. (2008) derived course resolution albedo on a $1-\mathrm{km}$ scale Advanced Very High Resolution Radiometer (AVHRR) data using the information extracted from 30-m resolution Thematic Mapper (TM) by two methods including arithmetic averaging of the albedo values retrieved from TM data and direct retrieval from AVHRR data. Using a corrective algorithm, they managed to considerably reduce the scaling errors on a regional course scale.

\section{Land surface representation in the regional climate model REMO: a practical example}

The REgional climate MOdel (REMO) is a three dimensional hydrostatic model for the atmosphere (Jacob 2001, Jacob et al. 2001). The model's prognostic variables include surface pressure, horizontal wind components, temperature, water vapour and cloud water content. REMO has been successfully tested and validated for several countries and regions (e.g., Raschke et al. 1998, Jacob et al. 2005, Hagemann \& Jacob 2007) with horizontal resolutions of $10 \mathrm{~km}, 20 \mathrm{~km}$, and 50 $\mathrm{km}$.

Land surface processes in REMO are controlled by physiological vegetation properties such as LAI, fractional vegetation cover, background albedo, surface roughness length due to vegetation, forest ratio, and soil water holding capacity. For each land cover type, these vegetation fields are allocated in the global dataset of Land Surface Parameters (Hagemann et al. 1999, Hagemann 2002). This information is aggregated to the model grid scale, by averaging the vegetation parameters of all land cover types located in each grid cell, weighted by their fractional areas within the cells.

Whereas albedo, LAI, and fractional vegetation cover display an annual cycle, the other parameters remain constant throughout the year. The seasonal variation in the LAI between its minimum and maximum value is provided using the monthly growth factor (Hagemann 2002), which is defined by the fraction of absorbed Photosynthetically Active Radiation (FPAR) in low and mid-latitudes. A global distribution of FPAR has been derived from Berthelot et al. (1994), based on NOAA-AVHRR data (Knorr 1997).

For the parameterization of background albedo, global distributions of soil and vegetation albedo have been produced (Rechid et al. 2007). They are derived from remotely sensed MODIS (Moderate-Resolution Imaging Spectroradiometer) products of the albedo for total short-wave broad bands and the FPAR. The separated soil and vegetation albedo database can be applied in climate modelling to describe the annual background albedo cycle as a function of the monthlyvarying LAI (Rechid et al. 2007).

As well as many other regional climate models, REMO works with fixed vegetation parameters per month, which have to be tested by comparing against periodical field observations or fine-scale remote sensing data. For example, Blümel \& Reimer (2009) calculated high-resolved LAI values of NOAA data for validation and compared them to the fixed LAI values which were used in the REMO model. The results demonstrated the vegetation development within the land-use classes well. In addition to the seasonal variations and the influence of various weather conditions on vegetation growth was also reflected in the calculated LAI values.

\section{Discussion and conclusion}

The practical importance of adequate representation of forest cover in regional climate models is increasing with land cover change through climate change, natural vegetation dynamics, or land use that have been shown to greatly affect climate.

Field observations play a crucial role in understanding water and energy exchange processes and validating the results of climate models. But measuring albedo and LAI on longer time scales and over large regions requires a great effort. Most observed data in a specific area are hardly adaptable for other regions. Alternatively, the basic advantages of remote sensing techniques against field observations are the following:

- They can provide continuous information over large areas, whereas field observations are carried out only at selected stations.

- Depending on the type of commercial sensor and spatial resolution, collection intervals of remote sensing data range from daily to monthly, whereas field measurements cover often short-term periods.

However, there are some uncertainties which may cause biases in LAI estimation using remote sensing data, including shadow and atmospheric effects in forest canopies (particularly in case of optical data), nonlinearity of LAI/vegetation index relationships, and background reflections in NDVI values.

The spectral and radiometric problems can 
be reduced integrating the new active remote sensing. High-density 3D topographic information (e.g., Airborne Laser Scanning) and sub-canopy and cloud-independent information on stand structure (e.g., RADAR systems) could be the most important areas for further development in this field. Although LiDAR height metrics improve the LAI estimation in forested areas (Pang et al. 2009), the use of them is still associated with high acquisition costs, especially when gathering small footprint data.

To overcome the possible non-linearities in regression analysis, the application of distribution-free models, i.e., non-parametric methods, could be effective when spatial prediction of LAI from remote sensing predictors is of particular interest. The moderate-resolution imagery, when combined with relevant indices (e.g., Soil Reflectance Index), were shown to be accurate predictors for non-parametric modelling of LAI in regional scales (Fang \& Liang 2005).

For the regional climate model REMO, the following remote sensing-supported improvements would be useful for forest cover description:

- Forest-types could be distinguished in detail using commercial remote sensing data featuring higher spectral/spatial resolution. As a consequence it may also be possible to allocate the annual cycle of albedo and LAI to each forest type. Therefore, regional differences in LAI and albedo of the different forest types could be shown.

- Annual cycles of other important vegetation parameters, e.g., roughness length due to vegetation, could be described.

As a drawback, the scaling (resolution) problem is one of the existing challenges to find the most suitable remote sensing data for climate modelling purposes. For example, LAI is consistent over different spatial resolutions (Zheng \& Moskal 2009), whereas albedo values show a relatively high variability in coarser scales (Liu et al. 2008) and depend on various factors (e.g., solar zenith angle, satellite sensors, imaging time, local soil characteristics, and soil moisture content).

Thus, a synthesis of research methods, i.e., to obtain the best data/area compatibility at the least costs, seems a future challenge to develop an effective remote sensing-supported characterization of vegetation attributes for climate models. More intense international collaboration in improving remote sensing and incorporating the resulting information into climate models is therefore essential.

\section{Acknowledgements}

This review has been written as final assignment of the International Summer School "HOWTOPC" organized by the "Nancy-Freiburg-Zürich" forest network and the Swiss Federal Research Institute of Forest, Snow and Landscape (WSL), in summer 2009, in Zürich-Switzerland. The authors would like to thank the reviewers for their valuable comments on the manuscript.

\section{References}

Berthelot B, Dedieu G, Cabot F, Adam S (1994). Estimation of surface reflectance and vegetation index using NOAA/AVHRR: methods and results at global scale. Communication for the $6^{\text {th }}$ International Symposium on Physical Measurements and Signatures in Remote Sensing, ISPRS. Val d'Isere, France.

Blümel B, Reimer E (2009). Validation of boundary layer parameters of climate model REMO: estimation of LAI from NOAA-AVHRR data for the Baltimos region. Theoretical and Applied Climatology (Special issue). - doi: 10.1007/ s00704-009-0164-3

Brakke TW, Kanemasu ET, Steiner JL, Ulaby FT, Wilson E (1981). Microwave radar response to canopy moisture, LAI and dry weight of wheat, corn, and sorghum. Remote Sensing of Environment 11: 207-220. - doi: 10.1016/0034-4257(81) 90020-1

Brovkin V, Claussen M, Driesschaert E, Fichefet T, Kicklighter D, Loutre MF, Matthews HD, Ramankutty N, Schaeffer M, Sokolov A (2006). Biogeophysical effects of historical land cover changes simulated by six Earth system models of intermediate complexity. Climate Dynamics 26 : 587-600. - doi: 10.1007/s00382-005-0092-6

Christensen JH, Christensen OB (2003). Severe summertime flooding in Europe. Nature 421: 805-806. - doi: 10.1038/421805a

Cohen WB, Maiersperger TK, Stith TG, Tumer DP (2003). An improved strategy for regression of biophysical variables and Landsat ETM+ data. Remote Sensing of Environment 84: 561-571. doi: 10.1016/S0034-4257(02)00173-6

Déqué $\mathrm{M}$, Jones RG, Wild $\mathrm{M}$, Giorgi $\mathrm{F}$, Christensen JH, Hassell DC, Vidale PL, Rockel B, Jacob D, Kjellstrom E, de Castro M, Kucharski F, van den Hurk B (2005). Global high resolution versus limited area model climate change projections over Europe: quantifying confidence level from PRUDENCE results. Climate Dynamics 25: 653-670.

Fang H, Liang S (2005). A hybrid inversion method for mapping leaf area index from MODIS data: experiments and application to broadleaf and needleleaf canopies. Remote Sensing of Environment 94 (3): 405-424. - doi: 10.1016/j.rse. 2004.11.001

Giorgi F, Bi X (2005). Updated regional precipitation and temperature changes for the $21^{\text {st }}$ century from ensembles of recent AOGCM simulations. Geophysical Research Letters 32: L21715.

Gonzalez-Sanpedro MC, Toan TL, Moreno J, Kergoat L, Rubio E (2008). Seasonal variations of LAI of agricultural fields retrieved from Landsat data. Remote Sensing of Environment 112: 810824. - doi: 10.1016/j.rse.2007.06.018

Hagemann S, Botzet M, Dümenil L, Machenhauer B (1999). Derivation of global GCM boundary conditions from $1 \mathrm{~km}$ land use satellite data. MPIM, Report 289, Hamburg, Germany.

Hagemann S (2002). An improved land surface parameter dataset for global and regional climate models. MPI-M, Report 336, Hamburg, Germany.

Hagemann S, Jacob D (2007). Gradient in the climate change signal of European discharge predicted by a multi-model ensemble. Climatic Change 81: 309-327. - doi: 10.1007/s10584-0069225-0

Inoue Y, Olioso A (2004). Estimating dynamics of $\mathrm{CO}_{2}$ flux in agro-ecosystems based on synergy of remote sensing and process modelling - a methodological study. In: "Global environmental change in the ocean and on land" (Shyomi et al. eds). Terrapub 2004, pp. 375-390.

Jacob D (2001). A note to the simulation of the annual inter-annual variability of the water budget over the Baltic Sea drainage Basin. Meteorology and Atmospheric Physics 77: 61-73 doi: $10.1007 / \mathrm{s} 007030170017$

Jacob D, Van den Hurk BJJM, Andræ U, Elgered G, Fortelius C, Graham LP, Jackson SD, Karstens U, Köpken CHR, Lindau R, Podzun R, Rockel B, Rubel F, Sass BH, Smith RNB, Yang $X$ (2001). A comprehensive model intercomparison study investigating the water budget during the BALTEX-PIDCAP Period. Meteorology and Atmospheric Physics 77: 19-43. - doi: 10.1007/ s007030170015

Jacob D, Goettel H, Jungclaus J, Muskulus M, Podzun R, Marotzke J (2005). Slowdown of the thermohaline circulation causes enhanced maritime climate influence and snow cover over Europe. Geophysical Research Letters 32: L21711. - doi: 10.1029/2005GL023286

Kawata Y, Ueno S (1995). The surface albedo retrieval of mountainous forest area from satellite MSS data. Applied Mathematics and Computations 69: 41-59. - doi: 10.1016/0096-3003(94) 00098-O

Knorr W (1997). Satellitengeschützte fernentkundung und modellierung des globalen $\mathrm{CO}_{2-}$ austausch der landvegetation: eine synthese. Examensarbeit 49, MPI-M Hamburg, Germany.

Kotz B, Schaepman M, Morsdorf F, Bowyer P, Itten K, Allgöwer B (2004). Radiative transfer modeling within a heterogeneous canopy for estimation of forest fire fuel properties. Remote Sensing of Environment 92: 332-344. - doi: 10.1016/j.rse.2004.05.015

Kwak DA, Lee WK, Cho HK (2007). Estimation of LAI using LiDAR remote sensing in forest. ISPRS Workshop on Laser Scanning and SilviLaser 2007, Espoo-Finland.

Lee KS, Park YI, Kim SH, Park, JH, Woo CS, Jang, KC (2004). Remote sensing estimation of forest LAI in close canopy situation. Proceedings of ISPRS conference, Istanbul, Turkey. [online] URL: https:/www.isprs.org/congresses/istanbul 2004/comm7/papers/77.pdf

Lewis P, Disney MI, Barnsley MJ, Muller JP (1999). Deriving albedo maps for HAPEX-Sahel from ASAS data using kernel-driven BRDF models. Hydrology and Earth Sytem Sciences 3 
(1): 1-13. - doi: 10.5194/hess-3-1-1999

Liu W, Hu B, Wang S (2008). Improving land surface pixel level albedo characterization using sub-pixel information retrieved from remote sensing. Proceedings of IGARSS2008, Boston, Massachusetts, USA. [online] URL: https:/www.igarss08.org/Abstracts/pdfs/4023.pdf Liu CH, Chen AJ, Liu GR (1994). Variability of the bare soil albedo due to different solar zenith angles and atmospheric haziness. International Journal of Remote Sensing 15 (13): 2531-2542. doi: 10.1080/01431169408954271

Lucht W, Schaaf C, Strahler AH, d'Entremont R (2000). Remote sensing of albedo using the BRDF in relation to land surface properties. In: "Observing land from space: science, customers and technology" (Verstraete MM, et al. eds). Kluwer Academic Publishers, pp. 175-186.

Mátyás C (2008). Ecological challenges of climate change in Europe's continental, droughtthreatened Southeast. In: "Regional aspects of climate-terrestrial-hydrologic interactions in nonboreal Eastern Europe" (Groisman PY, Sergiy VI eds). NATO Science Series, Springer Verlag, pp. 35-46.

McAllister DM, Valeo C (2007). A robust new method for the remote estimation of LAI in montane and boreal forests. International Journal of Remote Sensing 28 (8): 1891-1905. - doi: 10.1080/01431160600975311

Pang Y, Tan B, Solberg S, Li Z (2009). Forest LAI estimation comparison using LiDAR and hyperspectral data in boreal and temperate forests. In: "Remote Sensing and Modeling of
Ecosystems for Sustainability VI" (Gao W, Jackson TJ). Proceedings of the SPIE, vol. 7454, pp. 74540-74548

Pitman AJ (2003). Review the evolution of, and revolution in, land surface schemes designed for climate models. International Journal of Climatology. 23: 479-510.

Post DF, Fimbres A, Matthias AD, Sano EE, Accioly L, Batchily AK, Ferreira LG (2000). Predicting soil albedo from soil color and spectral reflectance data. Soil Science Society American Journal 64: 1027-1034. [online] URL: http://soil.scijournals.org/cgi/content/abstract/64/ 3/1027

Raschke E, Karstens U, Nolte-Holube R, Brandt $\mathrm{R}$, Isemer HJ, Hoffmann D, Lobmeyer M, Rockel B, Stuhlmann R (1998). The Baltic sea experiment BALTEX: a brief overview and some selected results of the authors. Surveys in Geophysics 19: 1-22. - doi: 10.1023/A: 1006567924820

Rechid D, Raddatz TJ, Jacob D (2007). Parameterization of snow-free land surface albedo as a function of vegetation phenology based on MODIS data and applied in climate modeling. Theoretical and Applied Climatology 95: 245255. - doi: 10.1007/s00704-008-0003-y

Richter K, Vuolo F, D'Urso G (2008). LAI and surface albedo estimation: comparative analysis from vegetation indexes to radiative transfer models. Proceedings of IGARSS2008, Boston, Massachusetts, USA. - [online] URL: http://www.igarss08.org/Abstracts/pdfs/2234.pdf Schär C, Vidale P L, Lüthi D, Frei C, Häberli C,
Liniger MA, Appenzeller C (2004). The role of increasing temperature variability in European summer heatwaves. Nature 427: 332-336. - doi: 10.1038 /nature 02300

Seneviratne, SI, Lüthi D, Litschi M, Schär C (2006). Land-atmosphere coupling and climate change in Europe. Nature 443: 205-209. - doi: 10.1038/nature05095

Soudani K, François C, Maire GL, Dantec VL, Dufrêne E (2006). Comparative analysis of IKONOS, SPOT, and ETM+ data for LAI estimation in temperate coniferous and deciduous forest stands. Remote Sensing of Environment 102: 161-175. - doi: 10.1016/j.rse.2006.02.004

Wardley NW, Curran PJ (1984). The estimation of green LAI from remotely sensed airborne multispectral scanner data. International Journal of Remote Sensing 5: 671-679. - doi: 10.1080/ 01431168408948850

Wilfong RT, Brown RH, et al. (1967). Relationships between leaf area index and apparent photosynthesis in Alfalfa (Medicago Sativa L.). and Ladino clover (Trifolium Repens L.). Crop Science 7 (1): 27-30. [online] URL: http://crop.scijournals.org/cgi/content/abstract/7/1/27

Wulder MA, Franklin SE (2003). Remote sensing of forest environments: concepts and case studies. Kluwer Academic Publishers, Boston, USA. Zheng M, Moskal MM (2009). Retrieving LAI using remote sensing: theories, methods and sensors. Sensors 9: 2719-2745. - doi: 10.3390/ s90402719 